\title{
CONTENTS
}

\author{
Volume 47 Number 1
}

The 2009 Applied Probability Trust Lecture

1 HENRIK HULT AND GENNADY SAMORODNITSKY. Large deviations for point processes based on stationary sequences with heavy tails

Research Papers

41 EDWARD POLLAK. Coalescent theory for a monoecious random mating population with a varying size

58 M. GONZÁLEZ, R. MARTÍNEZ AND M. SLAVTCHOVA-BOJKOVA. Stochastic monotonicity and continuity properties of the extinction time of Bellman-Harris branching processes: an application to epidemic modelling

72 MARIA VLASIOU AND ZBIGNIEW PALMOWSKI. Tail asymptotics for a random sign Lindley recursion

84 ANTONIO DI CRESCENZO AND BARBARA MARTINUCCI. A damped telegraph random process with logistic stationary distribution

97 MAY-RU CHEN AND SHOOU-REN HSIAU. Two new models for the two-person red-andblack game

109 KRZYSZTOF DȨBICKI, ABDELGHAFOUR ES-SAGHOUANI AND MICHEL MANDJES. Transient asymptotics of Lévy-driven queues

130 ONNO BOXMA, DAVID PERRY, WOLFGANG STADJE AND SHELLEY ZACKS. The busy period of an $\mathrm{M} / \mathrm{G} / 1$ queue with customer impatience

146 FRASER DALY. Stein's method for compound geometric approximation

157 FROSSO S. MAKRI. On occurrences of $F-S$ strings in linearly and circularly ordered binary sequences

179 M. T. ALODAT, M. AL-RAWWASH AND M. A. JEBRINI. Duration distribution of the conjunction of two independent $F$ processes

191 QUNQIANG FENG AND HOSAM M. MAHMOUD. On the variety of shapes on the fringe of a random recursive tree

201 MUSTAFA KHANDWAWALA AND RAJESH SUNDARESAN. Optimal multicommodity flow through the complete graph with random edge capacities

216 FILIA VONTA AND ALEX KARAGRIGORIOU. Generalized measures of divergence in survival analysis and reliability

235 JORGE NAVARRO, FRANCISCO J. SAMANIEGO AND N. BALAKRISHNAN. The joint signature of coherent systems with shared components

254 XIAOHU LI AND WEIYONG DING. Optimal allocation of active redundancies to $k$-out-of- $n$ systems with heterogeneous components

264 MICHEL M. DENUIT AND MHAMED MESFIOUI. Generalized increasing convex and directionally convex orders

277 JESÚS DE LA CAL AND JAVIER CÁRCAMO. Inverse stochastic dominance, majorization, and mean order statistics

Short Communications

293 SHAUL K. BAR-LEV, ONNO BOXMA AND GÉRARD LETAC. A characterization related to the equilibrium distribution associated with a polynomial structure 


\section{Research Papers}

301 JOSE BLANCHET AND JINGCHEN LIU. Efficient importance sampling in ruin problems for multidimensional regularly varying random walks

323 DIMITRIOS G. KONSTANTINIDES, KAI W. NG AND QIHE TANG. The probabilities of absolute ruin in the renewal risk model with constant force of interest

335 XUDONG ZENG. A stochastic differential reinsurance game

350 MUNEYA MATSUI AND THOMAS MIKOSCH. Prediction in a Poisson cluster model

367 DJILALI AIT AOUDIA AND ÉRIC MARCHAND. On the number of runs for Bernoulli arrays

378 GESINE REINERT AND ADRIAN RÖLLIN. Random subgraph counts and $U$-statistics: multivariate normal approximation via exchangeable pairs and embedding

394 MICHAEL TORTORELLA. On reliability prediction and semi-renewal processes

407 MOSHE SHAKED, MIGUEL A. SORDO AND ALFONSO SUÁREZ-LLORENS. A class of location-independent variability orders, with applications

426 RAMESH C. GUPTA AND RAMESHWAR D. GUPTA. Random effect bivariate survival models and stochastic comparisons

441 LOTHAR BREUER. A quintuple law for Markov additive processes with phase-type jumps

459 BRIAN H. FRALIX AND GERMÁN RIAÑO. A new look at transient versions of Little's law, and $\mathrm{M} / \mathrm{G} / 1$ preemptive last-come-first-served queues

474 A. J. FIELD AND P. G. HARRISON. Busy periods in fluid queues with multiple emptying input states

498 PASCAL MOYAL. The queue with impatience: construction of the stationary workload under FIFO

513 ALEXANDER IKSANOV AND MATTHIAS MEINERS. Exponential rate of almost-sure convergence of intrinsic martingales in supercritical branching random walks

526 CHUNHUA MA AND LONGMIN WANG. On estimation of the variances for critical branching processes with immigration

543 JOAQUÍN FONTBONA, NATHALIE KRELL AND SERVET MARTÍNEZ. Energy efficiency of consecutive fragmentation processes

562 ELCIO LEBENSZTAYN, FÁBIO PRATES MACHADO AND MAURICIO ZULUAGA MARTINEZ. Nonhomogeneous random walks systems on $\mathbb{Z}$

572 NETTA COHEN, JONATHAN JORDAN AND MARGARITIS VOLIOTIS. Preferential duplication graphs

\section{Short Communications}

586 ERIK EKSTRÖM, CARL LINDBERG, JOHAN TYSK AND HENRIK WANNTORP. Optimal liquidation of a call spread

594 PAVEL S. RUZANKIN. Approximation for expectations of unbounded functions of dependent integer-valued random variables

601 MAXIM FINKELSTEIN. A note on converging geometric-type processes 
Volume 47 Number 3

\section{Research Papers}

611 MARK FACKRELL, QI-MING HE, PETER TAYLOR AND HANQIN ZHANG. The algebraic degree of phase-type distributions

630 PEPA RAMÍREZ-COBO, ROSA E. LILLO AND MICHAEL P. WIPER. Nonidentifiability of the two-state Markovian arrival process

650 MIKKO S. PAKKANEN. Stochastic integrals and conditional full support

668 PENG ZUOXIANG, SARALEES NADARAJAH AND LIN FUMING. Convergence rate of extremes for the general error distribution

680 BING LU. Recovering a piecewise constant volatility from perpetual put option prices

693 A. KAPLUN. The continuous-time Ehrenfest process in term structure modelling

713 M. MÖHLE. Looking forwards and backwards in the multi-allelic neutral Cannings population model

732 SABIN LESSARD. Recurrence equations for the probability distribution of sample configurations in exact population genetics models

752 ALLAN GUT. Limit theorems for a generalized St Petersburg game

761 MITSUSHI TAMAKI. Sum the multiplicative odds to one and stop

778 ARMANDO F. MENDOZA-PÉREZ AND ONÉSIMO HERNÁNDEZ-LERMA. Asymptotic normality of discrete-time Markov control processes

796 ELCHANAN MOSSEL AND ARNAB SEN. Branching process approach for 2-SAT thresholds

811 MATTHIAS MEINERS. An almost-sure renewal theorem for branching random walks on the line

826 KATARZYNA RYBARCZYK AND DUDLEY STARK. Poisson approximation of the number of cliques in random intersection graphs

841 SRINIVASAN BALAJI, HOSAM MAHMOUD AND ZHANG TONG. Phases in the diffusion of gases via the Ehrenfest urn model

856 YURI KONDRATIEV, YURI KOZITSKY AND TANJA PASUREK. Gibbs random fields with unbounded spins on unbounded degree graphs

876 ZHENGCHENG ZHANG. Mixture representations of inactivity times of conditional coherent systems and their applications

Short Communications

886 RADHA KRISHNA GANTI AND MARTIN HAENGGI. Limit of the transport capacity of a dense wireless network

893 MICHEL DENUIT. Positive dependence of signals 


\section{Volume 47 Number 4}

\section{Research Papers}

899 HENRY W. BLOCK, NAFTALI A. LANGBERG, THOMAS H. SAVITS AND JIE WANG. Continuous mixtures of exponentials and IFR gammas having bathtub-shaped failure rates

908 YIQING CHEN, ANYUE CHEN AND KAI W. NG. The strong law of large numbers for extended negatively dependent random variables

923 SHUHONG ZHANG AND XIAOHU LI. Some new results on the moment generating function order and related life distributions

934 A. D. BARBOUR AND P. K. POLLETT. Total variation approximation for quasi-stationary distributions

947 F. DUFOUR AND A. B. PIUNOVSKIY. Multiobjective stopping problem for discrete-time Markov processes: convex analytic approach

967 JOE SUZUKI. A Markov chain analysis of genetic algorithms: large deviation principle approach

976 L. COUTIN, L. DECREUSEFOND AND J. S. DHERSIN. A Markov model for the spread of viruses in an open population

997 YAN DOLINSKY. Shortfall risk approximations for American options in the multidimensional Black-Scholes model

1013 MICHAEL R. TEHRANCHI. Characterizing attainable claims: a new proof

1023 A. KUZNETSOV. Wiener-Hopf factorization for a family of Lévy processes related to theta functions

1034 JEVGENIJS IVANOVS. Markov-modulated Brownian motion with two reflecting barriers

1048 BERNARDO D'AURIA, JEVGENIJS IVANOVS, OFFER KELLA AND MICHEL MANDJES. First passage of a Markov additive process and generalized Jordan chains

1058 JAMES C. FU AND TUNG-LUNG WU. Linear and nonlinear boundary crossing probabilities for Brownian motion and related processes

1072 PIETER ALLAART. A general 'bang-bang' principle for predicting the maximum of a random walk

1084 SERKAN ERYILMAZ. Discrete scan statistics generated by exchangeable binary trials

1093 KATSUNORI ANO, HIDEO KAKINUMA AND NAOTO MIYOSHI. Odds theorem with multiple selection chances

1105 G. NUEL. On the first $k$ moments of the random count of a pattern in a multistate sequence generated by a Markov source

1124 SVANTE JANSON, TOMASZ ŁUCZAK AND ILKKA NORROS. Large cliques in a power-law random graph

1136 BOJAN BASRAK. Limit theorems for the inductive mean on metric trees

1150 MARIA DEIJFEN. Random networks with preferential growth and vertex death

1164 F. PAPANGELOU. A simple model for random oscillations

1174 SIMEON M. BERMAN. Probabilistic analysis of the efficacy of periodic testing of employees

Short Communications

1191 PAWEŁ HITCZENKO. On tails of perpetuities

1195 OU ZHAO, MICHAEL WOODROOFE AND DALIBOR VOLNÝ. A central limit theorem for reversible processes with nonlinear growth of variance

Letter to the Editor

1203 ZBIGNIEW PALMOWSKI AND BERT ZWART. On perturbed random walks

1205 Index 


\section{BOOK ANNOUNCEMENT}

Peña, V. H., Lai, T. L. ANd Shao, Q.-M. (2009). Self-Normalized Processes is a volume in the series

\section{Probability and Its Applications}

published by Springer in collaboration with the Applied Probability Trust.

Self-normalized processes are of common occurrence in probabilistic and statistical studies. A prototypical example is Student's $t$-statistic introduced in 1908 by Gosset, whose portrait is on the front cover. Due to the highly nonlinear nature of these processes, the theory experienced a long period of slow development. In recent years there have been a number of important advances in the theory and applications of self-normalized processes. Some of these developments are closely linked to the study of central limit theorems, which imply that self-normalized processes are approximate pivots for statistical inference.

The present volume covers recent developments in the area, including selfnormalized large and moderate deviations, and laws of the iterated logarithms for self-normalized martingales. This is the first book that systematically treats the theory and applications of self-normalization.

\section{Contents}

1. Introduction

2. Classical Limit Theorems, Inequalities and Other Tools

3. Self-Normalized Large Deviations

4. Weak Convergence of Self-Normalized Sums

5. Stein's Method and Self-Normalized Berry-Esseen Inequality

6. Self-Normalized Moderate Deviations and Law of the Iterated Logarithm

7. Cramér-Type Moderate Deviations for Self-Normalized Sums

8. Self-Normalized Empirical Processes and $U$ Statistics

9. Martingale Inequalities and Related Tools

10. A General Framework for Self-Normalization
11. Pseudo-Maximization via Method of Mixtures

12. Moment and Exponential Inequalities for Self-Normalized Processes

13. Laws of the Iterated Logarithm for Self-Normalized Processes

14. Multivariate Self-Normalized Processes and Matrix Normalization

15. The $t$-Statistic and Studentized Statistics

16. Self-Normalization and Approximate Pivots for Bootstrapping

17. Pseudo-Maximization in Likelihood and Bayesian Inference

18. Sequential Analysis and Boundary Crossing Probabilities for Self-Normalized Statistics 


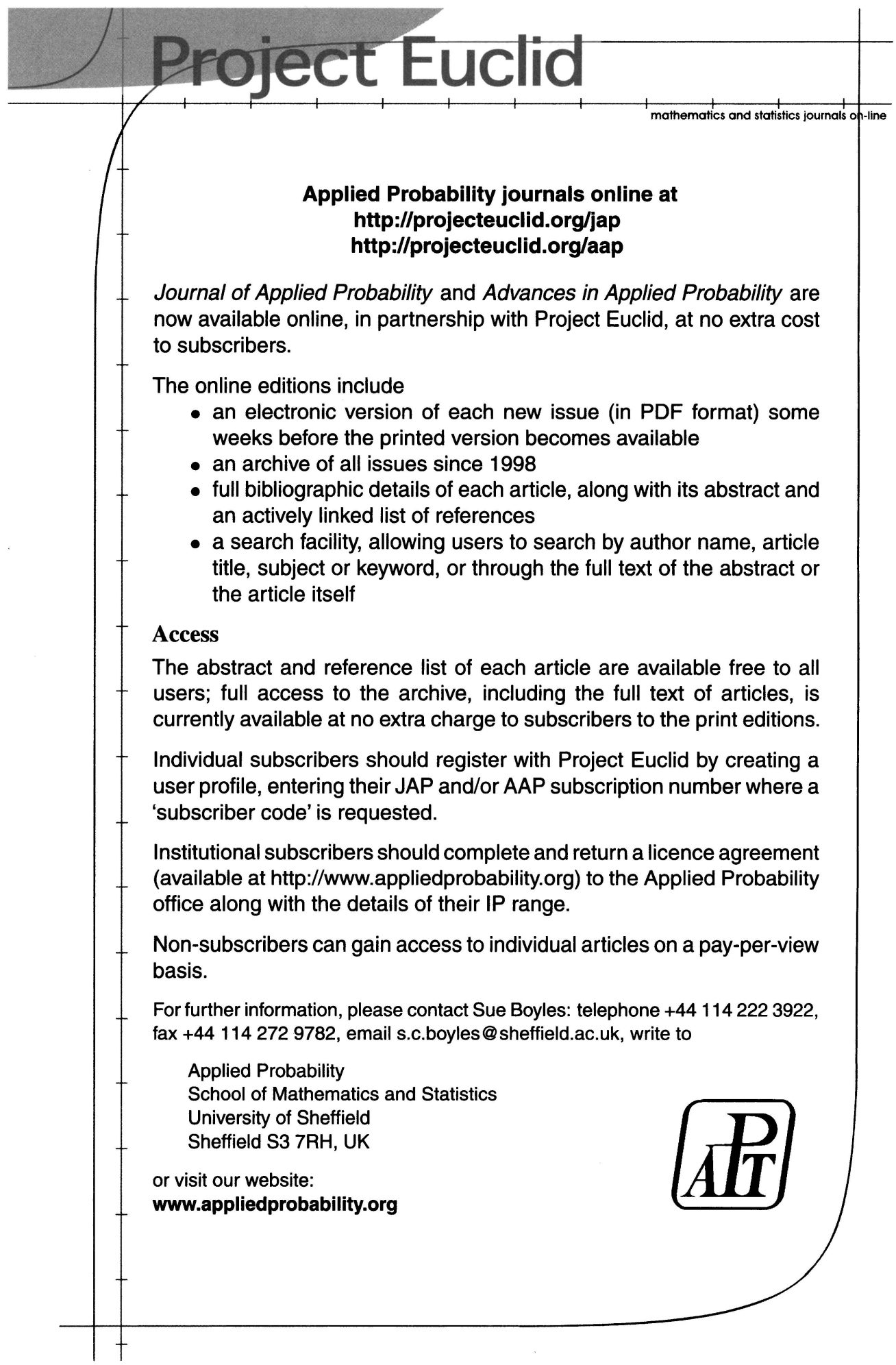




\section{Subscription rates}

Subscription rates for volume 47 (2010) of Journal of Applied Probability (JAP) are as follows (post free and including online access at http://projecteuclid.org/jap/): US\$312.00; A $\$ 390.00 ; £ 186.00$ for libraries and institutions; or US\$104.00; A \$130.00; $£ 62.00$ for individuals belonging to a recognised scientific society. The subscription rates for volume 42 (2010) of Advances in Applied Probability, the companion publication, are the same; if both journals are ordered directly from the Applied Probability office at the same time, the combined price is discounted by $10 \%$. Please send all enquiries to: Applied Probability Subscriptions, School of Mathematics and Statistics, University of Sheffield, Sheffield S3 7RH, UK (telephone +44 114222 3922; fax +44 114272 9782; email s.c.boyles@ sheffield.ac.uk). Cheques, money orders, etc. should be made payable to 'Applied Probability'. Payment is acceptable in US, Australian or UK currency, or by Visa or Mastercard. We can provide back issue prices on application.

\section{Notes for contributors}

Research papers are published in both Journal of Applied Probability (JAP) and Advances in Applied Probability $(A A P)$, with longer papers typically appearing in $A A P$. However, assignation of papers between the two journals is made by the Editor on an issue-by-issue basis. A submission to Applied Probability is considered as a submission to either journal. In addition, $A A P$ publishes letters specifically related to papers that have appeared in $A A P$ and $J A P$ publishes short communications of a few printed pages in the nature of notes and letters specifically related to papers that have appeared in $J A P$. Review papers and papers in stochastic geometry and statistical applications are published in AAP.

Fifty offprints of each paper will be provided free, with additional offprints available at cost.

Papers submitted to the Applied Probability journals are considered on the understanding that they have not been published previously and are not under consideration by another publication. Accepted papers will not be published elsewhere without the written permission of the Trust. Submitted papers should be in English. It is the author's responsibility to ensure an acceptable standard of language, and a paper failing to meet this requirement may go back to the author for rewriting before being sent out for review.

Papers should include: (i) a short abstract of 4-10 lines giving a non-mathematical description of the subject matter and results; (ii) a list of keywords detailing the contents; and (iii) a list of classifications, using the 2000 Mathematics Subject Classification scheme (http://www.ams.org/msc/). Letters to the Editor need not include these. To assist authors in writing papers in the Applied Probability style, they may use the LTEX class file aptpub.cls, available from http://www.appliedprobability.org/. Use of this class file is not a condition of submission, but will considerably increase the speed at which papers are processed.

Papers should be submitted as hard copy or as electronic files (with hard copy back-up). All submissions will be acknowledged on receipt and must be accompanied by a covering letter stating the author's postal address and affiliation. Hard copy: Send all submissions to the Applied Probability office in Sheffield, and not to individual editors. Two copies of the paper, at least one of which should be double spaced, should be sent to: Executive Editor, Applied Probability, School of Mathematics and Statistics, University of Sheffield, Sheffield S3 7RH, UK. Electronic submission: Please email a double-spaced PostScript ${ }^{\mathrm{TM}}$ (.ps) or portable document format (.pdf) file, not exceeding $1 \mathrm{Mb}$. The files must be clearly identified by name in a separate covering message. The address for email submissions is l.nash@sheffield.ac.uk. Authors should also submit one hard copy to the Executive Editor, as above.

\section{Copyright}

The copyright of all published papers is vested in the Applied Probability Trust. When a paper is accepted for publication, the Trust asks the authors to assign copyright by signing a form in which the terms of copyright are listed. Failure to do this promptly may delay or prevent publication.

Authorisation to photocopy items for internal or personal use, or the internal or personal use of specific clients, is granted by the Applied Probability Trust for libraries and other users registered with the Copyright Clearance Center (CCC) Transactional Reporting Service, provided that the corresponding processing and royalty fees (see http://www.copyright.com) are paid directly to CCC, 222 Rosewood Drive, Danvers, MA 01923, USA. 0021-9002/10 


\section{Volume 47 Number 4}

Research Papers

899 HENRY W. BLOCK, NAFTALI A. LANGBERG, THOMAS H. SAVITS AND JIE WANG. Continuous mixtures of exponentials and IFR gammas having bathtub-shaped failure rates

908 YIQING CHEN, ANYUE CHEN AND KAI W. NG. The strong law of large numbers for extended negatively dependent random variables

923 SHUHONG ZHANG AND XIAOHU LI. Some new results on the moment generating function order and related life distributions

934 A. D. BARBOUR AND P. K. POLLETT. Total variation approximation for quasi-stationary distributions

947 F. DUFOUR AND A. B. PIUNOVSKIY. Multiobjective stopping problem for discrete-time Markov processes: convex analytic approach

967 JOE SUZUKI. A Markov chain analysis of genetic algorithms: large deviation principle approach

976 L. COUTIN, L. DECREUSEFOND AND J. S. DHERSIN. A Markov model for the spread of viruses in an open population

997 YAN DOLINSKY. Shortfall risk approximations for American options in the multidimensional Black-Scholes model

1013 MICHAEL R. TEHRANCHI. Characterizing attainable claims: a new proof

1023 A. KUZNETSOV. Wiener-Hopf factorization for a family of Lévy processes related to theta functions

1034 JEVGENIJS IVANOVS. Markov-modulated Brownian motion with two reflecting barriers

1048 BERNARDO D'AURIA, JEVGENIJS IVANOVS, OFFER KELLA AND MICHEL MANDJES. First passage of a Markov additive process and generalized Jordan chains

1058 JAMES C. FU AND TUNG-LUNG WU. Linear and nonlinear boundary crossing probabilities for Brownian motion and related processes

1072 PIETER ALLAART. A general 'bang-bang' principle for predicting the maximum of a random walk

1084 SERKAN ERYILMAZ. Discrete scan statistics generated by exchangeable binary trials

1093 KATSUNORI ANO, HIDEO KAKINUMA AND NAOTO MIYOSHI. Odds theorem with multiple selection chances

$1105 \mathrm{G}$. NUEL. On the first $k$ moments of the random count of a pattern in a multistate sequence generated by a Markov source

1124 SVANTE JANSON, TOMASZ ŁUCZAKAND ILKKA NORROS. Large cliques in a power-law random graph

1136 BOJAN BASRAK. Limit theorems for the inductive mean on metric trees

1150 MARIA DEIJFEN. Random networks with preferential growth and vertex death

1164 F. PAPANGELOU. A simple model for random oscillations

1174 SIMEON M. BERMAN. Probabilistic analysis of the efficacy of periodic testing of employees

Short Communications

1191 PAWEŁ HITCZENKO. On tails of perpetuities

1195 OU ZHAO, MICHAEL WOODROOFE AND DALIBOR VOLNÝ. A central limit theorem for reversible processes with nonlinear growth of variance

Letter to the Editor

1203 ZBIGNIEW PALMOWSKI AND BERT ZWART. On perturbed random walks

1205 Index 